\section{Case Reports in Ophthalmology}

Case Rep Ophthalmol 2017;8:429-435

DOI: $10.1159 / 000479308$
Published online: August 8, 2017

(C) 2017 The Author(s)

Published by S. Karger AG, Basel www.karger.com/cop

This article is licensed under the Creative Commons Attribution-NonCommercial 4.0 International License (CC BY-NC) (http://www.karger.com/Services/OpenAccessLicense). Usage and distribution for commercial purposes requires written permission.

\title{
Laser-Induced Choroidal Neovascularizations: Clinical Study of 3 Cases
}

\author{
Wipada Laovirojjanakul ${ }^{a} \quad$ Thuss Sanguansak $^{a}$ Yosanan Yospaiboon $^{a}$ \\ Supat Sinawat ${ }^{\mathrm{b}}$ Suthasinee Sinawat ${ }^{\mathrm{a}}$ \\ ${ }^{a}$ Department of Ophthalmology, KKU Eye Center, Khon Kaen University, Khon \\ Kaen, Thailand; ${ }^{b}$ Department of Physiology, Khon Kaen University, Khon Kaen, Thailand
}

\section{Keywords}

Choroidal neovascularization · Laser photocoagulation · Laser-induced neovascularization

\begin{abstract}
Background: We report 3 patients with laser-induced choroidal neovascularization (CNV). Method: Retrospective, observational case series. Medical charts and photographs were reviewed. Results: Two patients with central serous chorioretinopathy who developed iatrogenic CNV after focal laser photocoagulation were treated with intravitreal ranibizumab injections. One patient with CNV secondary to thermal laser photocoagulation for diabetic macular edema was treated with photodynamic therapy (PDT). Visual improvement has been demonstrated in the patients treated with intravitreal ranibizumab injections, and their successful visual outcome was stable for more than 2 years. Stable visual acuity was also observed in the patient treated with PDT, no visual improvement was observed possibly due to the macular scar and macular ischemia. No systemic or ocular complications were detected among the 3 cases. Conclusion: To prevent a laser-induced CNV, it is critical to avoid heavy small-spot laser burns and repeated application. Patients should be monitored carefully for CNV after laser treatment. In our cases, PDT and intravitreal ranibizumab injections were effective for the treatment of laser-induced CNV.




\section{Case Reports in Ophthalmology}

\section{Introduction}

Choroidal neovascularization (CNV) following focal laser photocoagulation has been reported as possible complication in many conditions such as central serous chorioretinopathy (CSCR) [1, 2], diabetic macular edema (DME) [3], and branch retinal vein occlusion [4]. Among those, laser-induced CNV has been mostly reported in CSCR patients. Many treatment modalities have been used and have been reported to provide successful outcome. These treatments include photodynamic therapy (PDT) [5-8], intravitreal bevacizumab injections (IVB) $[9,10]$, and submacular membranectomy [11].

We herein describe the clinical course of 3 cases of iatrogenic CNV treated with PDT and intravitreal ranibizumab injections (IVR).

\section{Case Report}

Case 1

A 48-year-old man presented with persistent CSCR in the right eye. Pinpoint pigment epithelial leakage was treated with argon laser photocoagulation (power 150-200 mW, spot size $200 \mu \mathrm{m}$, exposure time 100-200 ms) (Fig. 1). His visual acuity (VA) improved to 20/20. Ten weeks after laser treatment, he noticed metamorphopsia and reduced vision. Fundus examination showed round subretinal hemorrhage nearly 1 disc diameter in size next to the laser scar. Pedunculated growth of CNV was demonstrated by optical coherence tomography (Fig. 2). The prominently classic CNV was detected by fundus fluorescein angiography (FFA) (Fig. 3). After 6 IVR, his VA has improved from 20/80 to 20/20. This successful outcome has sustained for 2 years.

\section{Case 2}

A 41-year-old woman with recurrent CSCR had diffuse retinal pigment epitheliopathy leakage demonstrated on FFA. She was treated with argon laser photocoagulation (power $200 \mathrm{~mW}$, spot size $200 \mu \mathrm{m}$, exposure time $200 \mathrm{~ms}$ ). Four weeks after treatment, her vision had improved to 20/20. Serous macular detachment was not detected. Two weeks later, she experienced distortion of vision. Juxtafoveal predominantly classic CNV was shown by FFA (Fig. 4). After 2 IVR, her VA improved from 20/400 to 20/30 and, thereafter, was stable throughout the 18 months' follow-up period.

\section{Case 3}

A 59-year-old man presented with submacular hemorrhage in the right eye 1 month after grid laser treatment for DME. His best corrected VA was 6/36. FFA demonstrated juxtafoveal CNV (Fig. 5). He was, therefore, treated with PDT. His VA, unfortunately, did not improve during the 6-month follow-up period possibly due to the macular scar and macular ischemia.

\section{Discussion}

In the past decades, indocyanine green angiography was not routinely used for the diagnosis of CNV and CSCR. Schatz et al. [2] reiterated that careful FFA evaluation was needed to be able to differentiate pre-existing CNV from laser-induced CNV. Matsunaga et al. [1] re- 


\section{Case Reports in Ophthalmology}

viewed 1,824 eyes after laser photocoagulation for CSCR; iatrogenic CNV was found in only 11 eyes $(0.60 \%)$. They suggested that pre-existing CNV may have been masked in CSCR patients who were older than 50 years and had weak parafoveal leaks. Secondary CNV - complicating laser treatment for DME - has also been reported. The pathogenesis, however, seems to be the same. The laser causes the break in the Bruch membrane and then initiates a proliferation of vessels from the choriocapillaries.

In our cases, laser-induced CNV, predominantly classic CNV, usually became apparent 25 weeks following laser photocoagulation, although it can occur years after treatment. Since there was no inciting disease to stimulate CNV progression, many cases were self-limited and VA can improve to $20 / 30$ or better. This type of CNV acted as a bridge to gap the break in the Bruch membrane. Among many treatment modalities, PDT has been used to treat most cases with laser-induced CNV [5-8]. PDT and IVB were more effective than submacular membranectomy, after which recurrent CNV could occur [11]. Laser-induced CNV in CSCR patients had better visual outcome than in DME patients and patients with retinal vein occlusion [5-8]. For laser-induced CNV in CSCR patients, the efficacy of PDT and IVB seem to be comparable, although there are some concerns with regard to the risk of choroidal ischemia as a complication after PDT [7-10,12].

From the literature review, no data on IVR has been published before. Herein, we found that both IVR and PDT were effective methods in treating laser-induced CNV. Recently, the results of the MINERVA study, a 12-month randomized clinical trial to evaluate the efficacy of ranibizumab in CNV associated with any cause other than not age-related macular degeneration and myopia, confirmed that ranibizumab is effective in managing CNV with a single injection, followed by a tailored PRN approach based on disease activity.

To prevent a laser-induced CNV, it is critical to avoid heavy small-spot laser burns and repeated application, especially within 0.5 disc diameter of the fovea which has greater pigmentation. The patient should be monitored carefully for CNV at the follow-up visits with repeat FFA if hemorrhage, increased turbidity of subretinal fluid, or thickening at the level of the retinal pigment epithelium, in, at, or adjacent to the area of laser application is noted.

\section{Statement of Ethics}

The authors have no ethical conflicts to disclose.

\section{Disclosure Statement}

The authors have no conflicts of interest or funding sources to disclose.

\section{References}

1 Matsunaga H, Nangoh K, Uyama M, Nanbu H, Fujiseki Y, Takahashi K: Occurrence of choroidal neovascularization following photocoagulation treatment for central serous retinopathy. Nippon Ganka Gakkai Zasshi 1995;99:460-468.

-2 Schatz H, Yannuzzi LA, Gitter KA: Subretinal neovascularization following argon laser photocoagulation treatment for central serous chorioretinopathy: complication or misdiagnosis? 1975. Retina 2012;32(suppl 1):0P893-OP906.

- 3 Varley MP, Frank E, Purnell EW: Subretinal neovascularization after focal argon laser for diabetic macular edema. Ophthalmology 1988;95:567-573. 


\section{Case Reports in \\ Ophthalmology}

\begin{tabular}{l|l}
\hline DOI: $10.1159 / 000479308$ & (c) 2017 The Author(s). Published by S. Karger AG, Basel \\
\hline
\end{tabular} www.karger.com/cop

Laovirojianakul et al: Laser-Induced Choroidal Neovascularizations: Clinical Study of 3 Cases
$>4$

Shah GK, Sharma S, Brown GC: Choroidal neovascularization following argon laser photocoagulation for macular edema associated with branch retinal vein obstruction. Can J Ophthalmol 2000;35:427-430.

-5 Shah GK: Photodynamic therapy for choroidal neovascularization after thermal laser photocoagulation for diabetic macular edema. Am J Ophthalmol 2003;135:114-116.

-6 Chan WM, Li KK, Liu DT, Lai TY, Chong KK, Lam DS: Photodynamic therapy with verteporfin in laserinduced choroidal neovascularization. Am J Ophthalmol 2003;136:565-567.

-7 Ergun E, Tittl M, Stur M: Photodynamic therapy with verteporfin in subfoveal choroidal neovascularization secondary to central serous chorioretinopathy. Arch Ophthalmol 2004;122:37-41.

-8 Cakir M, Cekic O, Yilmaz OF: Photodynamic therapy for iatrogenic CNV due to laser photocoagulation in central serous chorioretinopathy. Ophthalmic Surg Lasers Imaging 2009;40:405-408.

9 Nomura Y, Obata R, Yanagi Y: Intravitreal bevacizumab for iatrogenic choroidal neovascularization due to laser photocoagulation in central serous chorioretinopathy. Jpn J Ophthalmol 2012;56:245-249.

-10 Pikkel J, Rumelt S: Intravitreal bevacizumab for choroidal neovascularization secondary to laser photocoagulation for central serous chorioretinopathy. Eur J Ophthalmol 2012;22:488-491.

$>11$ Ha TW, Ham DI, Kang SW: Management of choroidal neovascularization following laser photocoagulation for central serous chorioretinopathy. Korean J Ophthalmol 2002;16:88-92.

$>12$ epithelial detachment and chronic central serous chorioretinopathy. Jpn J Ophthalmol 2009;53:52-56.

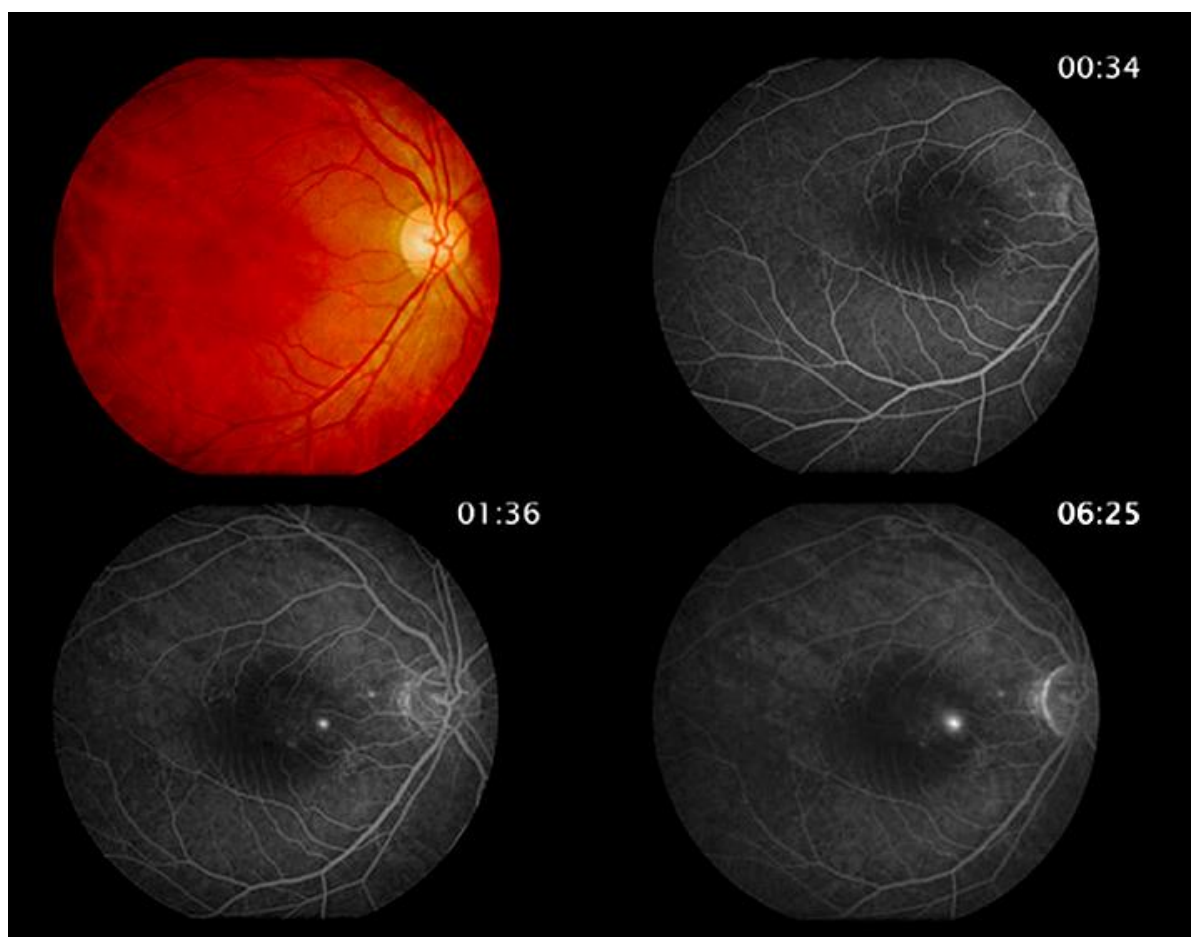

Fig. 1. Fundus image and fundus fluorescein angiography images of case 1 . Area of hypofluorescence due to subretinal fluid and small pin points of hyperfluorescence with ink blot pattern indicating central serous chorioretinopathy are presented. 


\section{Case Reports in Ophthalmology}

\section{4 weeks after focal laser}
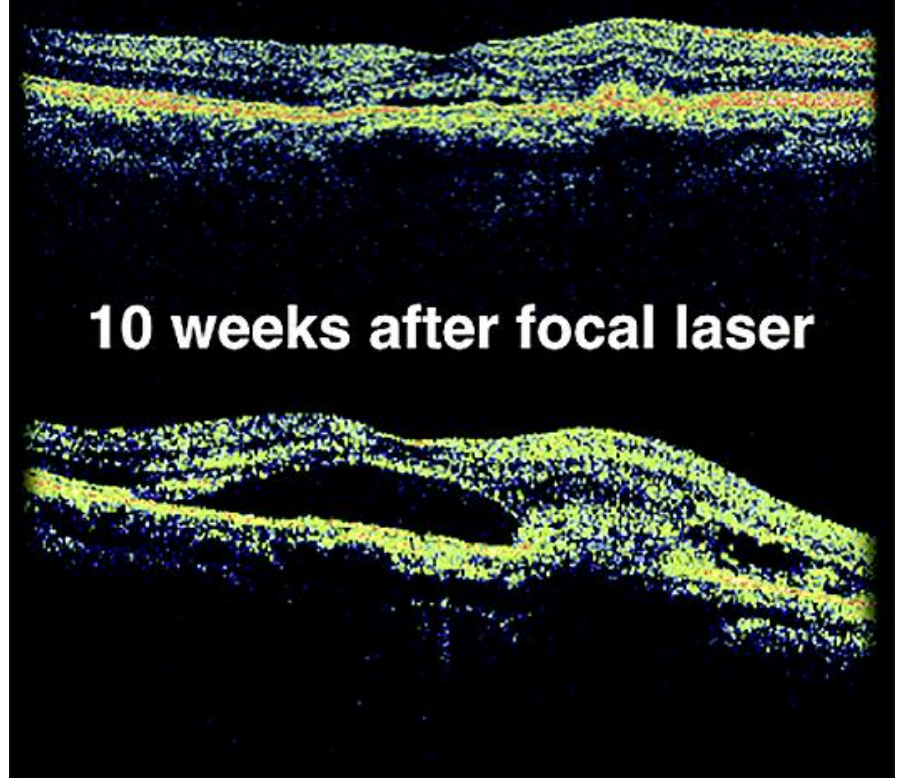

\section{after 6 ranibizumab injections}

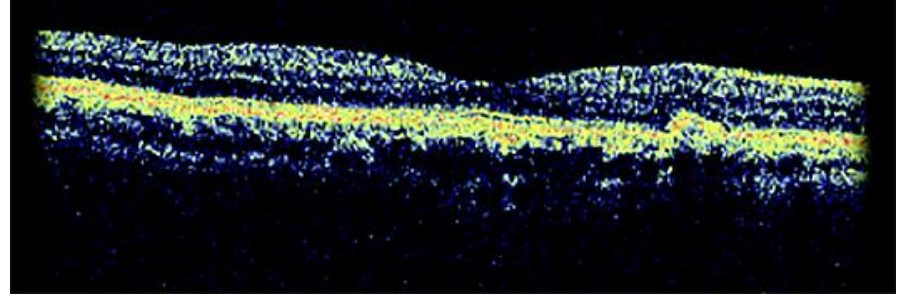

Fig. 2. Optical coherence tomography images of case 1 at 4 weeks, 10 weeks after focal laser, treating central serous chorioretinopathy. Last optical coherence tomography scan showed resolved subretinal fluid after treatment with ranibizumab injections. 


\section{Case Reports in Ophthalmology}

Case Rep Ophthalmol 2017;8:429-435

(c) 2017 The Author(s). Published by S. Karger AG, Basel www.karger.com/cop

Laovirojjanakul et al.: Laser-Induced Choroidal Neovascularizations: Clinical Study of 3 Cases

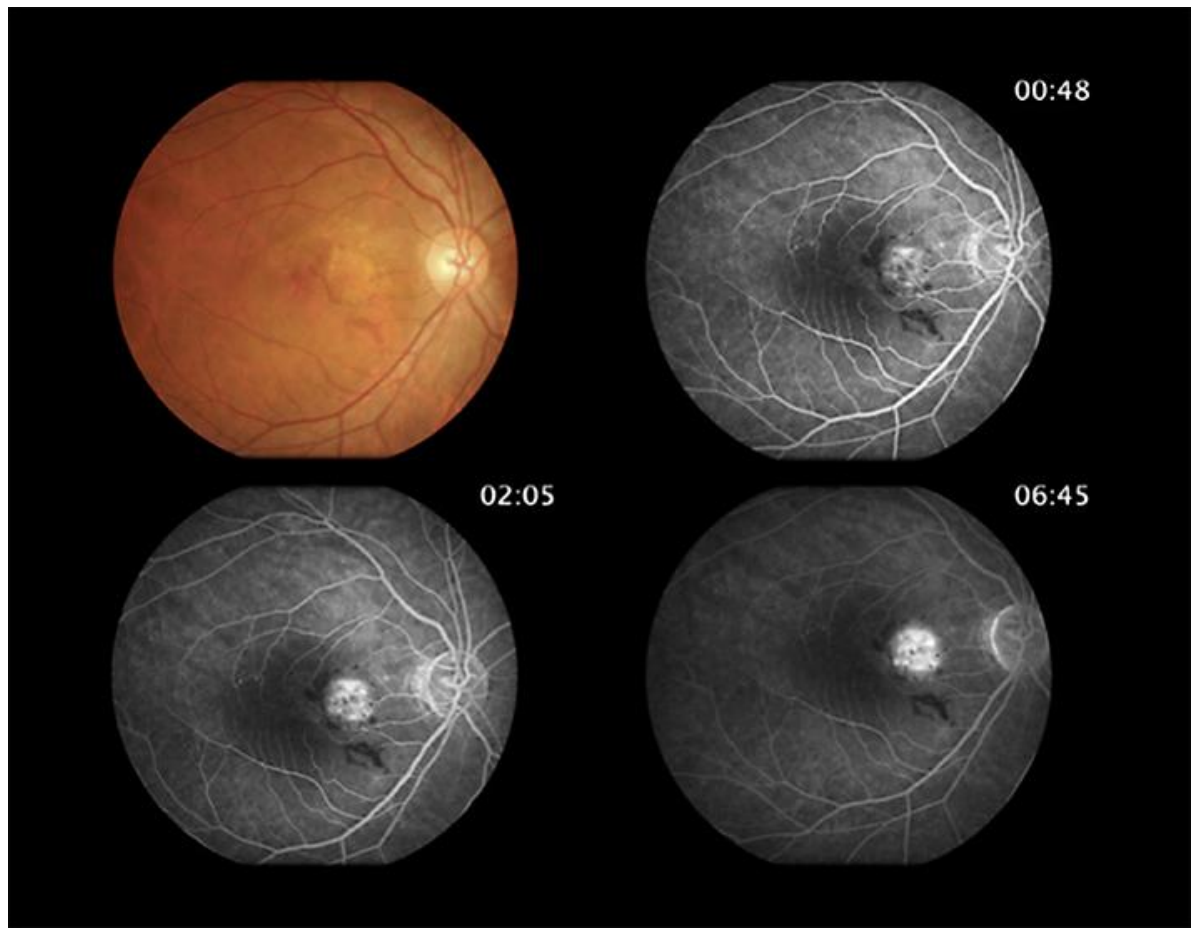

Fig. 3. Fundus image and fundus fluorescein angiography images of case 1. Area of abnormal hyperfluorescence in early and late phase indicating classic choroidal neovascularization is shown.
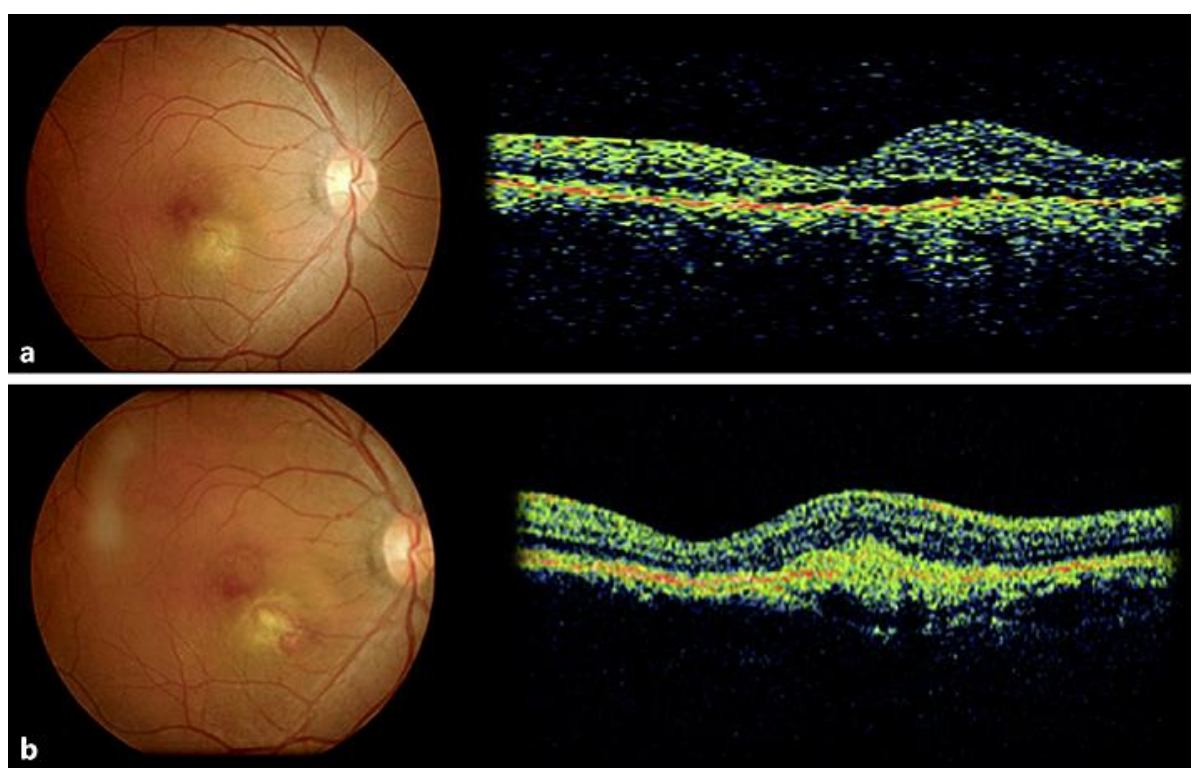

Fig. 4. Case 2. a Clear subretinal fluid on optical coherence tomography image with macular scar on fundus examination. b Six weeks after focal laser treatment, subretinal hemorrhage on fundus examination, which is concurrent with subretinal hyperreflective material on optical coherence tomography image. 
Case Reports in
Ophthalmology

Case Rep Ophthalmol 2017;8:429-435

DOI: $10.1159 / 000479308$

(c) 2017 The Author(s). Published by S. Karger AG, Basel www.karger.com/cop

Laovirojjanakul et al.: Laser-Induced Choroidal Neovascularizations: Clinical Study of 3 Cases

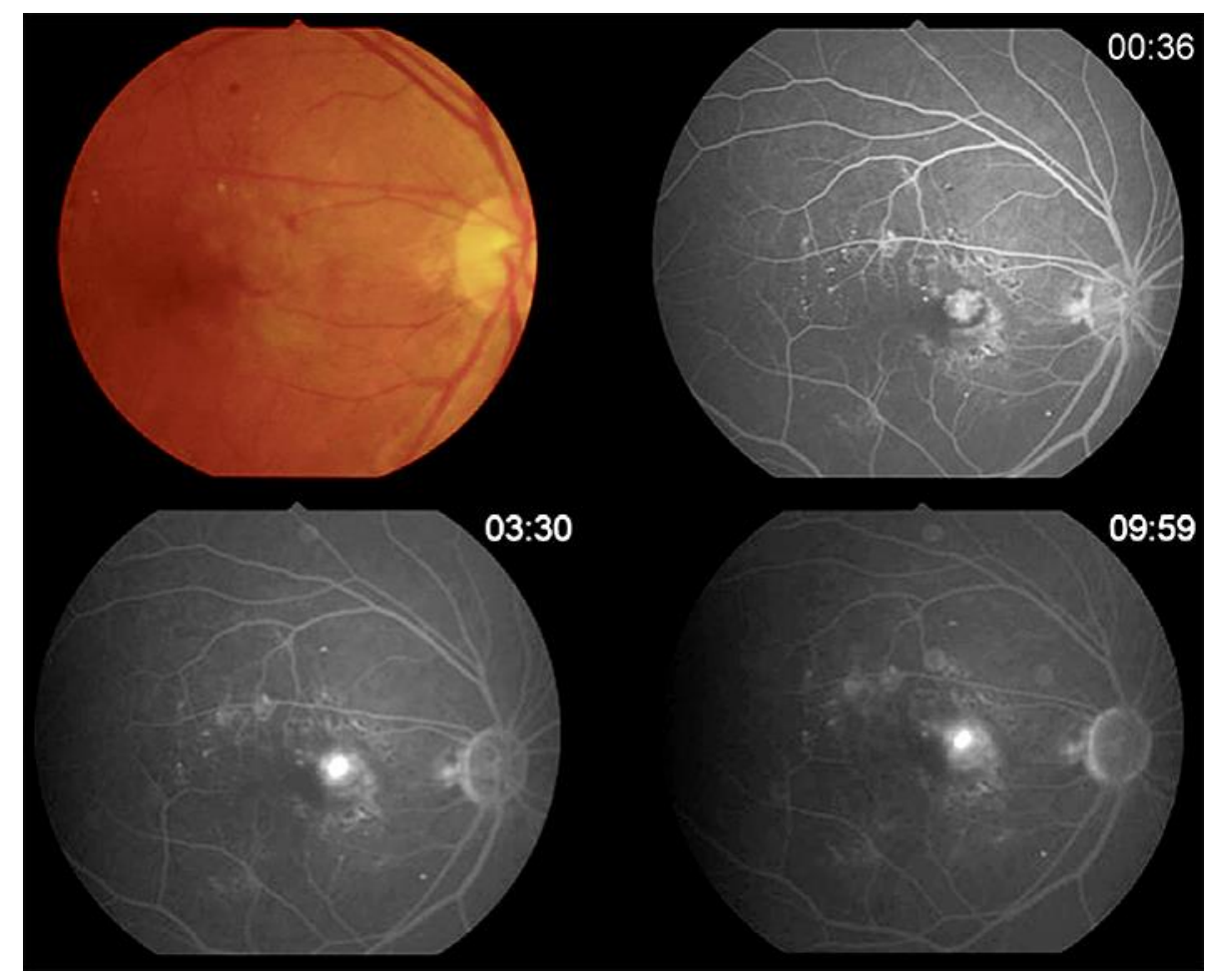

Fig. 5. Fundus image and fundus fluorescein angiography images of case 3. Area of abnormal hyperfluorescence in early and late phase indicating classic choroidal neovascularization. 